\title{
Paraspinal back muscles in asymptomatic volunteers: quantitative and qualitative analysis using computed tomography (CT) and magnetic resonance imaging (MRI)
}

\author{
Eun Kyung Khil ${ }^{1}$, Jung-Ah Choi ${ }^{1 *}$ (D), Eunjin Hwang ${ }^{1}$, Sabrilhakim Sidek ${ }^{2}$ and $\|$ Choi $^{3}$
}

\begin{abstract}
Background: To evaluate paraspinal back muscles of asymptomatic subjects using qualitative and quantitative analysis on CT and MRI and correlate the results with demographic data.

Methods: Twenty-nine asymptomatic subjects were enrolled prospectively (age: mean 34.31, range 23-50; 14 men, 15 women) from August 2016 to April 2017. Qualitative analysis of muscles was done using Goutallier's system on CT and MRI. Quantitative analysis entailed cross sectional area (CSA) on $C T$ and MRI, Hounsfield unit (HU) on $C T$, fat fraction using two-point Dixon technique on MRI. Three readers independently analyzed the images; intra- and inter-observer agreements were measured. Linear regression and Spearman's analyses were used for correlation with demographic data.

Results: CSA values were significantly higher in men $(p<0.001)$. Fat fraction was higher $(22.53 \%$ vs. $14.35 \%)$ and HU lower (36.00 vs. 47.43) in women $(p<0.001)$. Intra- and inter-observer reliabilities of the two methods were greater than 0.8 , except for CSA of L5/S1 on MRl; however, regarding quantitative analysis, decreasing $\mathrm{HU}$ and increasing fat fraction were correlated with increasing age, female gender and lower lumbar segment $(p<0.001)$.

Conclusion: MRI and CT can be reliably used for qualitative and quantitative analysis of paraspinal back muscles, regarding fat content. Fat fraction and HU showed highest reliabilities.

Keywords: Sarcopenia, MRI, Cross-sectional area, Fatty infiltration, Muscle atrophy, Two point Dixon, Fat fraction, Goutallier score, Paraspinal muscle
\end{abstract}

\section{Background}

Atrophy and degenerative changes in the back muscles are known to be associated with chronic lower back pain $[1,2]$. Studies have been conducted to investigate the relationship between low back pain, sarcopenia, and related pathologies [1, 3-5]. However, there have been few studies on analysis of paraspinal

\footnotetext{
* Correspondence: jachoi88@gmail.com

'Department of Radiology, Hallym University College of Medicine, Hallym University Dongtan Sacred Heart Hospital, 7, Keunjaebong-gil, Hwaseong-si, Gyeonggi-do 18450, South Korea

Full list of author information is available at the end of the article
}

back muscles in asymptomatic persons [6-10] and fewer studies in young adults $[1,6,10]$. Studies of lumbar paraspinal muscles are divided into two categories: qualitative and quantitative analysis by crosssectional area (CSA). For qualitative analysis, Goutallier grade (GG) system has been used extensively in CT and MRI studies of rotator cuff muscles [10-12]. However, there has been no standardized grading system to evaluate degenerative changes of paraspinal muscles in patients; several studies have applied the GG system to lumbar paraspinal muscles $[2,6,10$, $11,13]$. Lumbar paraspinal muscles are composed of

(c) The Author(s). 2020 Open Access This article is licensed under a Creative Commons Attribution 4.0 International License, which permits use, sharing, adaptation, distribution and reproduction in any medium or format, as long as you give appropriate credit to the original author(s) and the source, provide a link to the Creative Commons licence, and indicate if changes were made. The images or other third party material in this article are included in the article's Creative Commons licence, unless indicated otherwise in a credit line to the material. If material is not included in the article's Creative Commons licence and your intended use is not permitted by statutory regulation or exceeds the permitted use, you will need to obtain permission directly from the copyright holder. To view a copy of this licence, visit http://creativecommons.org/licenses/by/4.0/. The Creative Commons Public Domain Dedication waiver (http://creativecommons.org/publicdomain/zero/1.0/) applies to the data made available in this article, unless otherwise stated in a credit line to the data. 
various muscles and degree of fatty change varies according to lumbar level ${ }^{18}$; therefore, GG system has to be further validated in application to paraspinal muscles.

Some quantitative studies of paraspinal muscles have used the ratio of CSAs on CT or MRI [3, 5, 14-17]. However, it may be difficult to generalize CSAs to represent degenerative changes in lumbar paraspinal muscles because of differences in people's body composition. There have been studies evaluating functional CSA (fCSA), measuring areas without fatty changes, or total CSAs of the paraspinal muscles [3, 7, 16-18]. Other studies have used various fat quantification techniques to overcome shortcomings of quantitative techniques, including MR spectroscopy and chemical shift $[1,2,4,6$, $10,19,20]$. We used the two-point dixon technique because fat fraction (FF) can readily be obtained on a clinical scanner within reasonable time [21].

Although there have been several studies evaluating quality of lumbar paraspinal muscles, few studies have used CT and MRI comparing qualitative and quantitative methods [18]; fewer studies evaluated all lumbar segments. Therefore, in this study, we analyzed the lumbar paraspinal muscles both quantitatively and qualitatively on CT and MRI at all lumbar segments in young asymptomatic adults, regarding reliability of these methods and analyzed the correlation with demographic variables, especially regarding fat content.

\section{Methods}

\section{Study population}

This was a prospective study of asymptomatic healthy volunteers (age: mean 34.31, range 23-50; 14 men, 15 women) from August 2016 to April 2017; they were recruited from a health screening program, which usually gives the choice of having CT or MRI performed upon the subjects' choice; Institutional Review Board approval and written informed consent were obtained. Exclusion criteria were previous procedure and/or surgery of spine, hip, or knee, poliomyelitis or congenital anomalies in spine or lower extremity, and contraindications for MRI. Twenty-nine subjects were enrolled, clinically examined, and measured for height and weight with body mass index (BMI) as weight/height ${ }^{2}\left(\mathrm{~kg} / \mathrm{m}^{2}\right)$; all subjects underwent lumbar CT and MRI according to standardized protocols.

\section{$\mathrm{CT}$ and MR imaging}

Axial and sagittal reformatted images were acquired on a multidetector CT scanner (Somatom Definition AS or Somatom Definition Flash, Siemens, Erlangen, Germany) from T12 upper endplate margin to S2 lower endplate margin. CT scanning parameters were as follows: 100 to $120 \mathrm{kV}, 250-750 \mathrm{mAs}, 0.6 \mathrm{~mm}$ collimation, and $2 \mathrm{~mm}$ slice thickness. MRI was performed using a $3.0 \mathrm{~T}$ scanner (Skyra; Siemens, Erlangen, Germany). T2-weighted FSE (fast spin echo) axial and sagittal, T1-weighted axial sequences were acquired from L1-2 to L5-S1 centered at each intervertebral disc. Additionally, axial two-point Dixon sequence was obtained parallel to each vertebra (Table 1).

\section{Image analysis}

Two musculoskeletal radiologists (reader 1 with six-year experience, reader 3 with four-year experience) and a trainee (reader 2) independently analyzed images on Picture archiving and communicating system (PACS; Infinitt Co., Ltd., Seoul, Korea). We obtained axial images parallel to intervertebral discs on CT and MRI and selected an axial plane passing through the disc center (Fig. 1). On axial CT and MRI, regions of interest (ROIs) were manually drawn along the thoracolumbar fascia (Fig. 2); this corresponded to the "total CSA" referred to in previous studies, not "fCSA" $[9,16]$. We assessed inter- and intraobserver reliabilities of qualitative and quantitative measurements on CT and MRI. First, the three readers were trained by one experienced observer

Table 1 Parameter of L-spine MRI protocol

\begin{tabular}{|c|c|c|c|c|c|}
\hline Parameters & T2 weighted Sagittal & T1 weighted Sagittal & T2 weighted Axial & T1 weighted Axial & Two point Dixon \\
\hline Repetition time (ms) & 3040 & 504 & 2830 & 425 & 5.36 \\
\hline Echo time (ms) & 91 & 9.8 & 100 & 15 & $2.46-3.69$ \\
\hline Matrix number & $410 * 512$ & $269 * 448$ & $230 * 384$ & $230 * 384$ & $126 * 224$ \\
\hline Field of view (mm) & 320 & 320 & 160 & 160 & 196 \\
\hline Number of acquisition & 2 & 1 & 2 & 2 & 1 \\
\hline Echo train length & 19 & 5 & 16 & 3 & $x$ \\
\hline Section thickness (mm) & 3 & 3 & 4 & 4 & 3 \\
\hline Intersection gap (mm) & 0.6 & 0.6 & 0.4 & 0.4 & 0.6 \\
\hline Bandwidth (kHz/pixel) & 257 & 248 & 246 & 241 & 890 \\
\hline Acquisition time (min: sec) & $1: 54$ & $1: 30$ & 1:48 & 2:01 & $0: 15$ \\
\hline Flip Angle & 160 & 130 & 130 & 125 & 9 \\
\hline
\end{tabular}




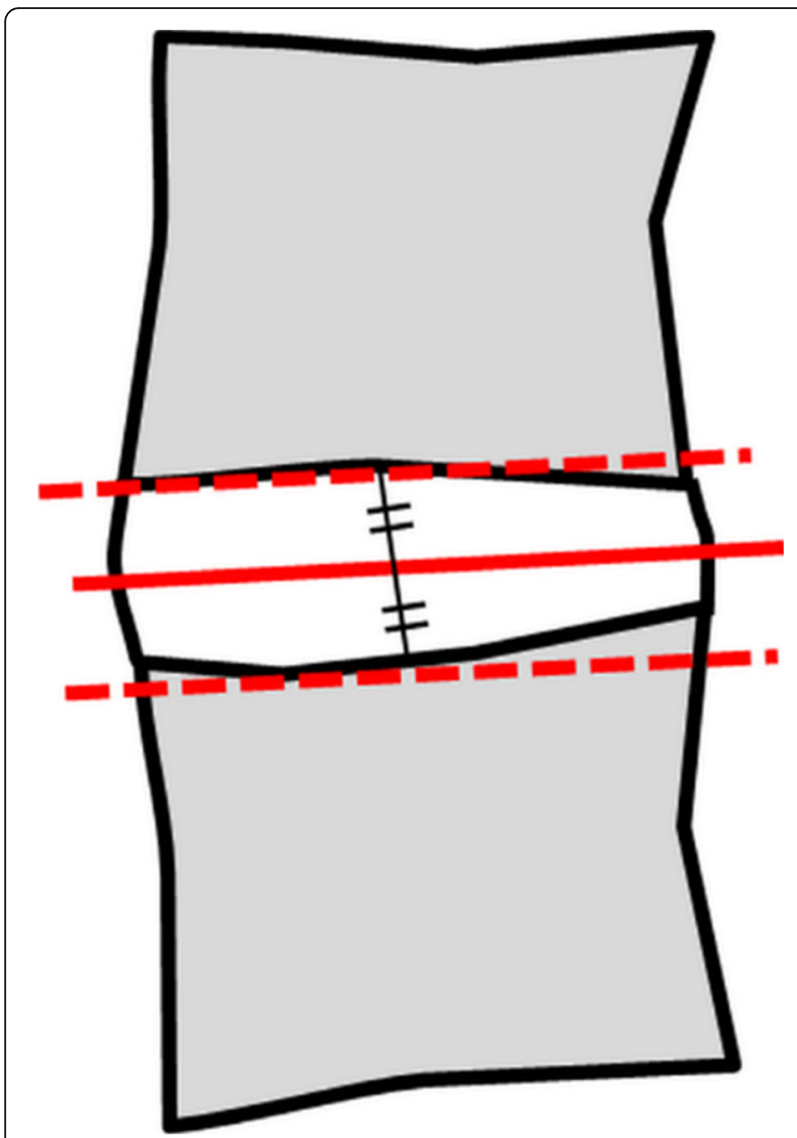

Fig. 1 A schematic diagram defining an axial plane in sagittal plane of CT and MRI. The axial plane was obtained by looking at the point parallel to the disc passing through the center of the disc height. And consecutive images were obtained according to $C T$ and $M R$ parallel to the central line how to draw ROIs and measure GGs under consensus and analyzed images blinded to each other's results. Measurements were repeated after 2 weeks for intraobserver agreement. We noted the presence of disc pathologies if there were any.

\section{Qualitative analysis}

Paraspinal muscles within the thoracolumbar fascia were evaluated using GGs on CT and MRI at L1-2 to L5-S1 segments as follows: 0 - all muscle, no fat, 1 - fatty streaks within muscle or fat stripe around lamina and facet joint, 2 - more muscle than fat, 3 - muscle equal to fat, 4 - more fat than muscle (Fig. 3).

\section{Quantitative analysis}

On CT, three radiologists drew ROIs on axial images to measure Hounsfield units (HU) and CSAs (Fig. 2a). On MRI, in-phase and fat only image were obtained using two-point Dixon method with ROIs drawn on in-phase image (Fig. 2b), which were copied and pasted onto fat only image (Fig. 2c); CSA and mean signal intensity (SI) were measured. FFs were calculated by dividing SI of the fat image ROI by SI of the in-phase image ROI. Additionally, on both CT and MRI, the values were corrected using the ROI of the vertebral body $(\mathrm{VB})$ to reduce bias such as body size and gender that could affect the CSA. The ROI was drawn along the margin of the $\mathrm{VB}$ at the inferior endplate of each lumbar level and then divides the measured CSA by this value $[19,22]$.

\section{Statistical analysis}

Demographic data were analyzed using T-test for parametric variables and Mann-Whitney U-test for nonparametric variables. For qualitative analysis, Kappa statistic was used for intra-observer agreement, Kendall's coefficient of concordance for inter-observer agreement.

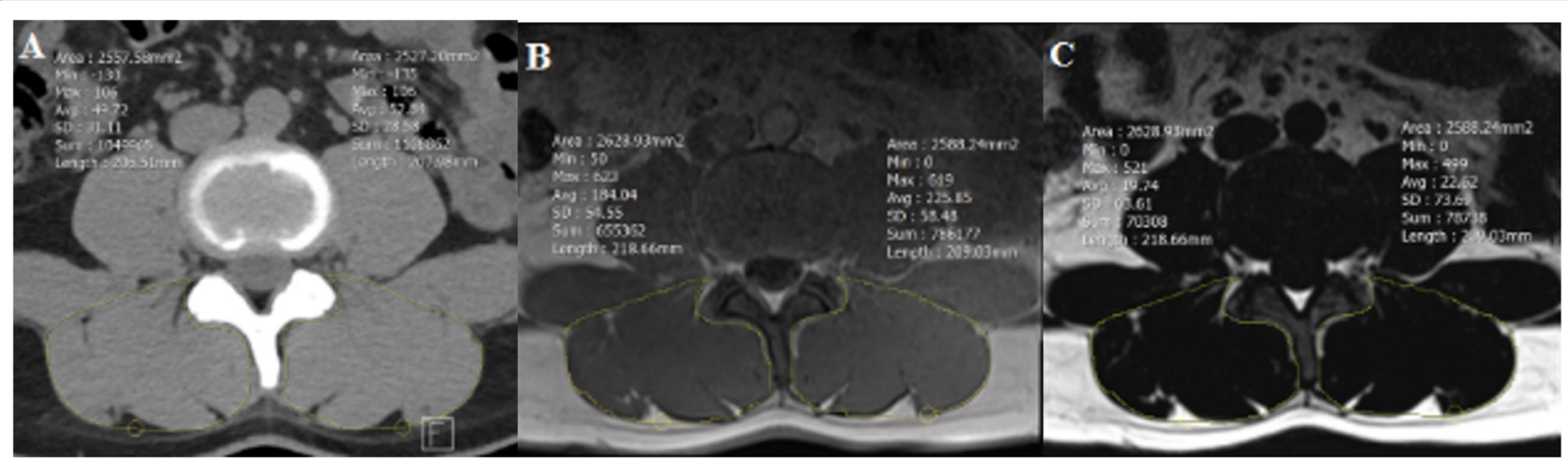

Fig. 2 Image shows an example of the region of interest (ROI) of the paraspinal back muscle on axial plane and acquisition of the quantitative measurement values on PACS workstation. On CT (a), when the ROI is drawn, mean CSA (cross sectional area) and mean HU (Hounsfield unit) are displayed on screen. On MRI (b), when the ROI is drawn on in-phase image of two-point Dixon technique, the CSA and signal intensity values are displayed as on CT, and the ROI is copied and pasted onto the fat only image (c), then CSA and signal intensity measured 
For quantitative analysis, intra-class correlation coefficient (ICC) was used for intra- and inter-observer agreements. Since GGs of paraspinal muscles were analyzed at 5 lumbar segments, it was impossible to obtain one representative value. We evaluated the relationship between demographic variables, including age, sex, BMI, and quantitative values. Also, we analyzed associations between quantitative values and each lumbar segment, i.e. whether there was an increase according to lumbar segment. Associations were analyzed using simple linear regression analysis; additional multiple linear regression analysis was performed for age, sex, and BMI, regarding their influence. Relationship between GG and quantitative values were analyzed using simple linear regression. Spearman's correlation analysis was used to evaluation of correlation between mean FF/HU and each lumbar segment, and then determine which lumbar segment best reflected the mean FF and HU. Kappa values can be interpreted as follows: under 0.20 slight agreement, $0.21-0.40$ fair agreement, 0.41-0.60 moderate; correlation coefficient $(r)$ indicated the degree of relevance as follows: $0.2-0.4$ week, $0.4-0.7$ moderate, $0.7-0.9$ strong, over 0.9 very strong. Statistical analyses were performed using SPSS 20.0 software (SPSS Inc., Chicago, IL, USA) with significance for $P<.05$.

\section{Results}

Regarding demographic data, height, weight, and BMI were significantly higher in males as expected (Table 2). Upon analysis of incidental disc pathologies, the results were as follows: there 5 disc protusions in L3/4, L4/5, L5/S1 and no disc extrusion. Qualitative and quantitative values of paraspinal muscles of each lumbar segment are summarized (Table 3). GGs scored between 0 and 2 on $\mathrm{CT}$ and MRI. Mean GG increased down the lumbar segments and was higher in women; GGs on MRI were higher than CT in both genders.

Mean CSA of men and women were $2519.67 \mathrm{~mm}^{2} /$ $2297.59 \mathrm{~mm}^{2}$ and $1848.24 \mathrm{~mm}^{2} / 1729.00 \mathrm{~mm}^{2}$ on CT/ MRI, respectively: mean CSA and the CSA ratio of men were mostly significantly higher than women on CT/ MRI. CSAs decreased at lower segments. CSAs on CT and MRI were comparable, except for L5-S1 level. Mean $\mathrm{HU}$ values were $47.43( \pm 4.30)$ in men and $36.00( \pm 6.38)$ in women; HU values decreased at lower levels. Mean FF was $14.35 \%( \pm 3.68)$ in men and $22.53 \%( \pm 5.93)$ in women; FFs increased at lower segments. On analysis of incidental disc pathologies and degenerative changes of 145 lumbar segments, 6 disc protrusions and 11 bulging discs were found, however, all asymptomatic.

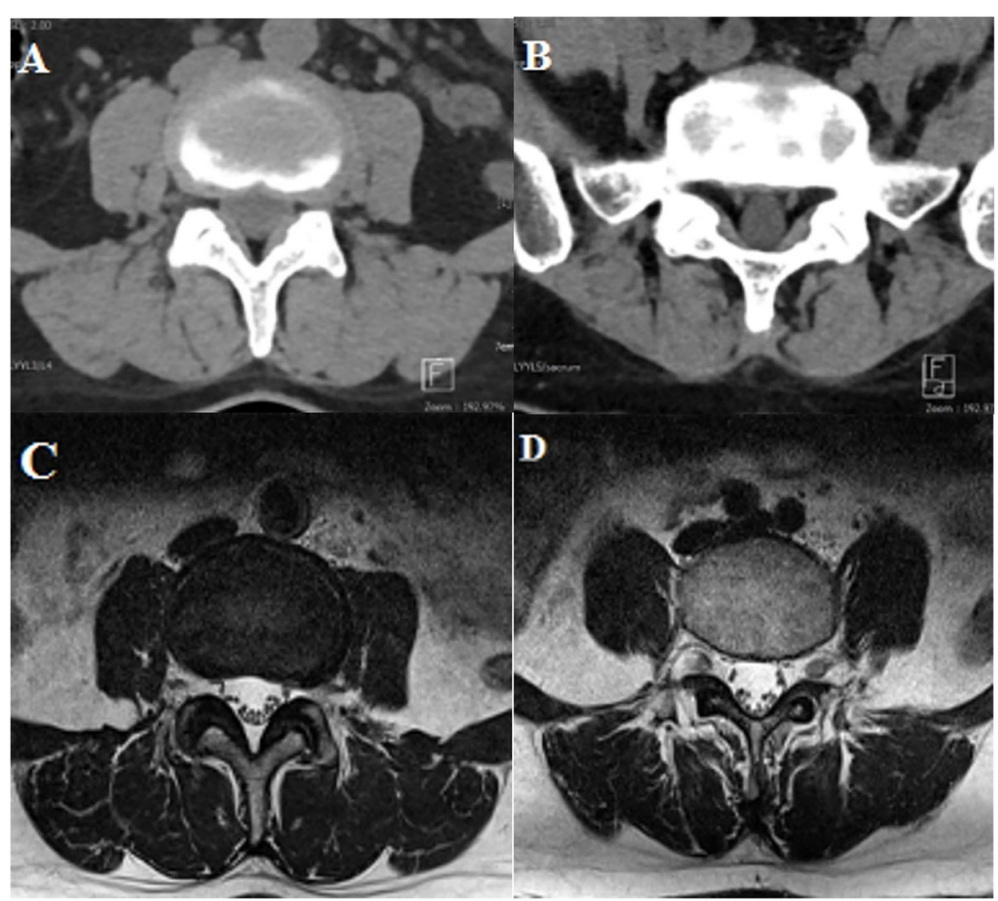

Fig. 3 An example of Goutallier grading system on CT (a, b) and MRI (c, d) in a 49-year old woman. a grade l: low density fat is observed around the vertebral lamina. $\mathbf{b}$ grade II: The fat surrounding three borders of the multifidus muscle is observed, and there was atrophy change. $\mathbf{c}$ grade I: In the axial T2-weighted image, there is fatty streak in the paraspinal muscles and fat surrounding the lamina. $\mathbf{d}$ grade II: on axial T2-weighted images, the amount of fat in the muscle is increased and accompanied by atrophic change 
Table 2 Descriptive statics of demographics data for 29 healthy volunteers

\begin{tabular}{|c|c|c|c|c|c|c|c|}
\hline & Mininum & Maximum & Mean & Standard deviation & Men $(n=14)$ & Women $(n=15)$ & $p$-value \\
\hline Age (year) & 23.00 & 50.00 & 34.31 & 8.59 & $33.14 \pm 6.83$ & $35.40 \pm 10.09$ & $0.81^{*}$ \\
\hline Height (cm) & 155.00 & 186.00 & 169.91 & 10.18 & $178.58 \pm 6.03$ & $161.81 \pm 5.31$ & $<0.001$ \\
\hline Weight (kg) & 49.00 & 94.00 & 66.97 & 13.52 & $77.41 \pm 9.41$ & $57.22 \pm 8.51$ & $<0.001$ \\
\hline BMI $\left(\mathrm{kg} / \mathrm{m}^{2}\right)$ & 19.30 & 29.40 & 22.98 & 2.64 & $24.27 \pm 2.66$ & $21.77 \pm 2.01$ & 0.008 \\
\hline Fat fraction (\%) & 9.69 & 29.25 & 18.44 & 6.39 & $14.35 \pm 3.68$ & $22.53 \pm 5.93$ & $<0.001$ \\
\hline $\mathrm{HU}$ & 25.93 & 53.45 & 41.52 & 7.92 & $47.43 \pm 4.30$ & $36.00 \pm 6.38$ & $<0.001$ \\
\hline MR CSA $\left(\mathrm{mm}^{2}\right)$ & 1440.38 & 2921.77 & 2013.29 & 403.08 & $2297.59 \pm 282.26$ & $1729.00 \pm 289.29$ & $<0.001$ \\
\hline $\mathrm{CT} \operatorname{CSA}\left(\mathrm{mm}^{2}\right)$ & 1529.25 & 3436.73 & 2172.38 & 479.15 & $2519.67 \pm 404.06$ & $1848.24 \pm 272.74$ & $<0.001$ \\
\hline
\end{tabular}

Using t-test, *using Mann-Whitney U test; BMI Body mass index, HU Hounsfiled unit, CSA Cross sectional area

\section{Intra- and inter-observer reliability}

For intraobserver reliability, regarding qualitative analysis on $\mathrm{CT}$, in reader 1 , there was substantial to almost perfect agreement (Kappa value 0.78-0.84) in all levels except for L1-2 level. In readers 2 and 3, Kapppa values were $0.74-1.0$ and $0.76-1.0$, respectively. On MRI, values of reader 1,2 , and 3 ranged between $0.78-1.0$, $0.73-0.93$, and $0.81-1.0$, respectively. Regarding quantitative analysis, Kappa values were higher than 0.9 for FF and $\mathrm{HU}$ in all readers. For CSAs, values were 0.9 or higher at all levels, except for L5/S1 level on MRI in all readers.

For inter observer reliability, ICCs for GGs were 0.830.92 and $0.87-0.93$ for CT and MRI, respectively. ICCs for CSA on CT were 0.95-0.97, on MRI were 0.94-0.98 at levels L1-2 to L4-5; the lowest ICC was 0.61 at level L5-S1. For HU and FFs on CT and MRI, ICCs were 0.9 or higher at all lumbar segments.

\section{Association analysis}

Mean quantitative values were analyzed regarding the relationship between age, sex, and BMI; the influence of each variable was measured by simple regression analysis
(Table 4). CSAs showed no significant difference according to lumbar segment on CT but significantly decreased down lower segments on MRI $(p<0.001)$. HU decreased and FF significantly increased down lumbar segments $(p<0.001)$. Additionally, we analyzed correlation between qualitative and quantitative values; right and left side values were comparable. As GGs increased, CSA decreased on CT and MRI, respectively, which was significant on CT $(p=0.002)$ but not on MRI. However, as GGs increased, HU decreased and FF increased $(p<$ 0.001).

Regarding CSAs on CT and MRI, there were significant correlations with sex and BMI (Table 5). CSA was smaller in women and as BMI increased, CSA significantly increased on CT and MRI $(p<0.001)$. HU and FF were statistically correlated with age and sex but not with BMI. Lower HU and higher FF were observed in women $(p<0.001)$. Gender was the most influential variable for $\mathrm{HU}$ and FF; BMI was the most influential variable for CSA.

When each lumbar level was analyzed for the most representative FF and $\mathrm{HU}, \mathrm{FF}$ at $\mathrm{L} 3-4$ was the most representative in all readers; FF showed a strong correlation

Table 3 The qualitative and quantitative values of the paraspinal muscles in each lumbar segment

\begin{tabular}{|c|c|c|c|c|c|c|c|c|c|c|c|c|c|c|c|c|}
\hline \multirow{3}{*}{$\begin{array}{l}\text { L- } \\
\text { spine } \\
\text { level }\end{array}$} & \multicolumn{8}{|l|}{ Men } & \multicolumn{8}{|c|}{ Women } \\
\hline & \multicolumn{4}{|l|}{$C T$} & \multicolumn{4}{|l|}{ MRI } & \multicolumn{4}{|l|}{$\mathrm{CT}$} & \multicolumn{4}{|l|}{ MRI } \\
\hline & GG & $\begin{array}{l}\text { CSA of } \\
\text { PM } \\
\left(\mathrm{mm}^{2}\right)\end{array}$ & $\begin{array}{l}\text { CSA } \\
\text { ratio }\end{array}$ & $\mathrm{HU}$ & $\mathrm{GG}$ & $\begin{array}{l}\text { CSA of } \\
\text { PM } \\
\left(\mathrm{mm}^{2}\right)\end{array}$ & $\begin{array}{l}\text { CSA } \\
\text { ratio }\end{array}$ & $\begin{array}{l}\text { Fat } \\
\text { fraction } \\
(\%)\end{array}$ & $\mathrm{GG}$ & $\begin{array}{l}\text { CSA of } \\
\text { PM } \\
\left(\mathrm{mm}^{2}\right)\end{array}$ & $\begin{array}{l}\text { CSA } \\
\text { ratio }\end{array}$ & $\mathrm{HU}$ & $\mathrm{GG}$ & $\begin{array}{l}\text { CSA of } \\
\text { PM } \\
\left(\mathrm{mm}^{2}\right)\end{array}$ & $\begin{array}{l}\text { CSA } \\
\text { ratio }\end{array}$ & $\begin{array}{l}\text { Fat } \\
\text { fraction(\%) }\end{array}$ \\
\hline L1/2 & $0.00^{*}$ & 2475.52 & $171.64^{*}$ & 52.55 & $0.30^{*}$ & 2464.85 & $197.43^{*}$ & 8.15 & $0.07^{*}$ & 1608.45 & $139.07^{*}$ & 45.91 & $0.74^{*}$ & 1634.75 & $161.21^{*}$ & 13.33 \\
\hline $\mathrm{L} 2 / 3$ & 0.20 & 2587.25 & $168.86^{*}$ & 51.46 & 0.53 & 2635.92 & $191.29 *$ & 10.17 & $0.29 *$ & 1827.64 & $144.6^{*}$ & 42.24 & $0.93^{*}$ & 1851.84 & $165.07^{*}$ & 15.77 \\
\hline L3/4 & $0.23^{*}$ & 2687.26 & $165.36^{*}$ & 47.96 & $0.83^{*}$ & 2624.13 & 175.57 & 13.52 & 0.75 & 1953.68 & $147.73^{*}$ & 38.32 & 1.11 & 1968.90 & 161.93 & 21.07 \\
\hline$\llcorner 4 / 5$ & 1.00 & 2651.20 & 159.71 & 44.66 & 1.37 & 2419.63 & 164.36 & 16.88 & 1.43 & 2090.03 & 160.47 & 30.65 & 1.17 & 1971.08 & 171.64 & 27.63 \\
\hline L5/S1 & $1.40^{*}$ & $2197.15^{*}$ & 143.51 & 40.53 & $1.87^{*}$ & $1343.42^{*}$ & $101.86^{*}$ & 23.01 & 1.82 & $1764.43^{*}$ & 141.25 & 22.89 & 1.89 & $1218.41^{*}$ & $121.21^{*}$ & 34.84 \\
\hline Total & 0.57 & $2519.67^{*}$ & $387.36^{*}$ & 47.43 & 0.98 & $2297.59^{*}$ & 166.14 & 14.35 & 0.87 & $1848.24^{*}$ & $299.71^{*}$ & 36.00 & 1.27 & 1728.99* & 156.22 & 22.53 \\
\hline
\end{tabular}

GG Mean Goutallier grade, CSA Cross sectional area, PM Paraspinal muscle, CSA ratio Paraspinal muscle CSA/vertebral body CSA*100, HU Hounsfield unit In GG (between both men and women), '*' means $p<.05$ using Mann-Whitney $\mathrm{U}$ test

In CSA, CSA ratio (between both men and women), '*'means $p<.05$ using T-test 
Table 4 The relationship between quantitative analysis methods and age, sex, MRI, L-spine level, and the relationship between quantitative and qualitative methods by linear regression analysis

\begin{tabular}{|c|c|c|c|c|c|c|c|c|c|c|c|c|}
\hline \multirow[t]{3}{*}{ Variable } & \multicolumn{6}{|c|}{$\mathrm{CSA}\left(\mathrm{mm}^{2}\right)$} & \multirow{2}{*}{\multicolumn{3}{|c|}{$\frac{\mathrm{HU}}{\mathrm{CT}}$}} & \multirow{2}{*}{\multicolumn{3}{|c|}{$\begin{array}{l}\text { Fat fraction (\%) } \\
\text { MRI }\end{array}$}} \\
\hline & \multicolumn{3}{|l|}{$\mathrm{CT}$} & \multicolumn{3}{|l|}{ MRI } & & & & & & \\
\hline & $B$ & SE & $p$-value & $B$ & SE & $p$-value & $B$ & SE & $p$-value & B & SE & $p$-value \\
\hline Age & -6.00 & 10.67 & 0.578 & -2.72 & 9.08 & 0.767 & -0.51 & 0.15 & 0.002 & 0.45 & 0.11 & 0.001 \\
\hline \multicolumn{13}{|l|}{ Sex } \\
\hline male & 1 & & & 1 & & & 1 & & & 1 & & \\
\hline female & -671.43 & 127.21 & $<0.001$ & -568.59 & 108.02 & $<0.001$ & -11.43 & 2.04 & $<0.001$ & 8.18 & 1.86 & $<0.001$ \\
\hline BMI & 147.77 & 20.38 & $<0.001$ & 120.46 & 19.41 & $<0.001$ & 1.10 & 0.54 & 0.050 & -0.87 & 0.45 & 0.065 \\
\hline L-spine level & 5.61 & 31.28 & 0.858 & -158.63 & 32.58 & $<0.001$ & -4.47 & 0.52 & $<0.001$ & 4.57 & 0.42 & $<0.001$ \\
\hline \multicolumn{13}{|c|}{ Goutallier grade } \\
\hline Right & -164.72 & 51.28 & 0.002 & -334.02 & 56.45 & 0.229 & -11.21 & 0.67 & $<0.001$ & 6.13 & 0.87 & $<0.001$ \\
\hline Left & -178.81 & 56.85 & 0.002 & -345.25 & 60.74 & 0.143 & -10.98 & 0.65 & $<0.001$ & 6.13 & 0.87 & $<0.001$ \\
\hline
\end{tabular}

$B$ Linear regression coefficient, SE Standard error, CSA Cross sectional area, HU Hounsfield unit

with $\mathrm{r}$ value of 0.9 or more, except at L5-S1 level. HU on CT showed the highest values at levels L2-3 and L45 , with $r$ values of 0.9 or higher.

\section{Discussion}

Muscle degeneration with fatty change is associated with lumbar spine pathology affecting disease progression and life quality $[5,15,20,23]$. Although CT and MRI are known to be accurate and sensitive in muscle evaluation $[24,25]$, there has been a few studies on paraspinal muscles in asymptomatic young adults using both modalities $[6-9,19]$. As MRI techniques have evolved recently, validation and comparison in healthy adults are needed. In our study, subjects were relatively young adults, matched by gender with a mean BMI of $23.0 \mathrm{~kg} / \mathrm{m}^{2}$.

GGs ranged between 0 and 2 in our study, consistent with previous studies [2, 10], increasing down lower lumbar segments, showing highest degree of fatty degeneration in L5-S1 segment, consistent with previous studies [26]. Although GGs correlated with quantitative analysis, we found a limitation in applying GGs to evaluate back muscles of young adults since higher degree of muscle degeneration (grades 3,4) were not seen and fatty changes were seen only in parts of paraspinal muscles close to spine; in spite of this, interobserver agreement of GGs was high.

GGs showed statistically significant differences between genders on CT and MRI; scores on MRI tended to be higher because MRI is more sensitive in detecting fat $[19,20,27]$. However, regarding CSA values, there was no statistically significant difference between CT and MRI, except for L5-S1 segment. Axial images using two-point Dixon technique were acquired parallel to each vertebra unlike conventional axial images. The angle between L5 and S1 vertebral bodies was large, and so CSA on two-point Dixon sequence and axial plane of CT were measured differently, resulting in lower interobserver agreement at L5-S1 segment on MRI.

CSAs were significantly higher in men on CT and MRI but did not show a significant difference according to age, consistent with previous studies $[6,14]$ and contradictory to other studies hypothesizing increased degenerative muscle changes with aging [15, 23]. This may be due to our study population, consisting of

Table 5 The association analysis between the quantitative analysis methods and three variables by multiple linear regression

\begin{tabular}{|c|c|c|c|c|c|c|c|c|c|c|c|c|}
\hline \multirow[t]{3}{*}{ Variable } & \multicolumn{6}{|l|}{$\mathrm{CSA}\left(\mathrm{mm}^{2}\right)$} & \multicolumn{3}{|l|}{$\mathrm{HU}$} & \multicolumn{3}{|c|}{ Fat fraction (\%) } \\
\hline & \multicolumn{3}{|l|}{$\mathrm{CT}$, Adj $\mathrm{R}^{2}=0.779$} & \multicolumn{3}{|l|}{ MRI, Adj R $R^{2}=0.765$} & \multicolumn{3}{|c|}{$C T, \operatorname{Adj} R^{2}=0.730$} & \multicolumn{3}{|c|}{ MRI, Adj R $R^{2}=0.663$} \\
\hline & $B(\beta)$ & SE & $p$-value & $B(\beta)$ & SE & $p$-value & $\overline{B(\beta)}$ & SE & $p$-value & $B(\beta)$ & SE & $p$-value \\
\hline Age & & & & & & & $-0.43(-0.46)$ & -0.09 & $<0.001$ & $0.38(0.519)$ & 0.08 & $<0.001$ \\
\hline Sex & $-393.79(-0.42)$ & 95.56 & $<0.001$ & $-365.32(-0.46)$ & 86.23 & $<0.001$ & $-10.47(-0.67)$ & 1.54 & $<0.001$ & $7.14(0.569)$ & 1.42 & \\
\hline BMI & $111.14(0.61)$ & 18.44 & $<0.001$ & $87.56(0.56)$ & 16.98 & $<0.001$ & & & & & & \\
\hline
\end{tabular}

$B$ Linear regression coefficient, $\beta$ Standardized linear regression coefficient, SE Standard error, Adj $R^{2}$ Adjusted R square, CSA Cross sectional area, $H U$ Hounsfield unit, $B M I$ Body mass index 
relatively young asymptomatic volunteers. Increased CSA was strongly associated with increasing BMI. As CSA does not accurately reflect muscle quality in young adults, BMI has limitations in assessing muscle quality. In our study, association of BMI with $\mathrm{HU}$ or FF was not statistically significant. Only quantifying fat could accurately evaluate the quality of paraspinal muscles.

$\mathrm{HU}$ and FF data were consistent with the hypothesis that fatty degeneration of paraspinal muscles increases with age [6,15]; fatty change tended to increase down lower segments, more pronounced in women, consistent with previous studies [20, 28]. Fortin et al. [16] proposed the most abundant fatty change to occur at L5-S1 segment because the gravitational centerline passes through this segment rendering it to be the most weight-bearing; also, a larger lordotic angle and greater motion at this level may contribute to this finding [16].

Previous studies have attempted to find the lumbar level, most representative of the mean [6]; Crawford et al. [6] noted L4-5 segment to be the most representative FF on MRI. We expected that the mid-lumbar level would best reflect fatty changes, because fatty change increased down lumbar levels, reflected in decreasing $\mathrm{HU}$ and increasing FF. From our results, all lumbar segments seemed to reflect the mean value well on CT and MRI. This may be because the study included only asymptomatic adults and difference in the correlation coefficient among the levels was not significant. The level that best reflected the mean was L2-3 segment for $\mathrm{HU}$ and L3-4 segment for FF; correlation coefficient was lower at L5S1 segment than other levels. We hypothesized a fatty change with muscle atrophy in the lower lumbar segments, most prominent in L5/S1. Similar to our study, a 15-year prospective study of quantitative analysis of paraspinal muscles also showed greater atrophy and fatty changes in muscle at L5/S1 [16].

Regarding qualitative analysis, intra- and interobserver agreements for CSA were high, consistent with previous studies [9, 18], confirming CSA reliable for muscle evaluation. Also using FF and $\mathrm{HU}$, more reliable values were obtained, comparable to CSA. Recently, two-point Dixon technique has been used to quantify fat in paraspinal muscles [6]. Since two-point Dixon technique acquires four phases with one acquisition, images are obtained in a reasonable scan time. In addition, on CT, it is easy to measure the degree of fatty change using only HU. Therefore, FF and HU are feasible and reliable tools for evaluation of muscle quality, especially regarding fatty degeneration.

This study has several limitations. First, sample size was small and did not include a wide age range. However, we obtained data of lumbar paraspinal muscles in asymptomatic relatively young adults, which have not been studied much. Secondly, this study reflects the characteristics of a certain ethnicity and may not reflect a diverse population. Thirdly, although asymptomatic healthy adults were recruited, there were some disc pathologies; however, they were all asymptomatic and probably did not have a significant effect on our results. Fourthly, there was no gold standard for muscle degeneration; however, it is neither feasible nor ethical to obtain muscle tissue specimens in a study like this and lack of gold standard is exactly the reason for such studies. Finally, we did not subdivide muscle groups; we analyzed all muscles in the thoracolumbar fascia as a whole as this seemed to be a simple and easy method.

\section{Conclusion}

Female, older age, and lower lumbar segment were associated with higher fat content of paraspinal muscles. MRI and CT can be reliably used for qualitative and quantitative analyses of paraspinal back muscles in young healthy adults, especially regarding fat content, with good correlation between the two methods. FF and HU could be useful tools for evaluating muscle degeneration with fatty change in paraspinal muscles. The level that best reflected the mean was L2-3 segment for $\mathrm{HU}$ and L3-4 segment for FF. This study could serve as a baseline study for future studies regarding muscles.

\begin{abstract}
Abbreviations
CT: Computed tomography; MRI: Magnetic resonance imaging; CSA: Cross sectional area; HU: Hounsfiled unit; GG: Goutallier grade; fCSA: Functional cross sectional area; FF: Fat fraction; BMI: Body mass index; FSE: Fast spin echo; ROIs: Regions of interests; SI: Signal intensity; ICC: Intra-class correlation coefficient
\end{abstract}

\section{Acknowledgements}

We thank Deok Yeon Jo, MS, for helping in statistical analysis and editing of the manuscript.

\section{Authors' contributions}

JAC and IC conceived and planned this study. JAC and EKK performed the experiments. EKK, EH, and SS performed the measurement and analysis of the data. JAC and IC aided in interpreting the results. EKK and JAC drafted and edited the manuscript in consultation with IC. All authors discussed the results and commented on the manuscript. The authors read and approved the final manuscript

\section{Funding}

This study was supported by Hallym University Research Fund 2016 (HURF2016-35) and by a grant from the Central Medical Service (CMS) Research Fund.

\section{Availability of data and materials}

The dataset analyzed are not publicly available but are available from the corresponding author on reasonable request.

\section{Ethics approval and consent to participate}

This study has been approved by the Hallym University Dontan Sacred Heart Hospital IRB (2016-246-I) and written informed consent was obtained.

Consent for publication

Not applicable.

Competing interests

The authors declare that they have no conflict of interest. 


\section{Author details}

'Department of Radiology, Hallym University College of Medicine, Hallym University Dongtan Sacred Heart Hospital, 7, Keunjaebong-gil, Hwaseong-si, Gyeonggi-do 18450, South Korea. ${ }^{2}$ Medical Imaging Unit, Faculty of Medicine, Universiti Teknologi MARA (UiTM) Sg Buloh Campus, 47000 Sg, Buloh, Selangor, Malaysia. ${ }^{3}$ Department of Neurosurgery, Hallym University Dongtan Sacred Heart Hospital, 7, Keunjaebong-gil, Hwaseong-si, Gyeonggi-do 18450, South Korea.

Received: 18 March 2020 Accepted: 16 June 2020

Published online: 26 June 2020

\section{References}

1. Paalanne N, Niinimaki J, Karppinen J, Taimela S, Mutanen P, Takatalo J, et al. Assessment of association between low back pain and paraspinal muscle atrophy using opposed-phase magnetic resonance imaging: a populationbased study among young adults. Spine (Phila Pa 1976). 2011;36(23):1961-8.

2. Mengiardi B, Schmid MR, Boos N, Pfirrmann CW, Brunner F, Elfering A, et al. Fat content of lumbar paraspinal muscles in patients with chronic low back pain and in asymptomatic volunteers: quantification with MR spectroscopy. Radiology. 2006;240(3):786-92.

3. Fortin M, Lazary A, Varga PP, McCall I, Battie MC. Paraspinal muscle asymmetry and fat infiltration in patients with symptomatic disc herniation. Eur Spine J. 2016;25(5):1452-9.

4. Bhadresha A, Lawrence OJ, McCarthy MJ. A comparison of magnetic resonance imaging muscle fat content in the lumbar Paraspinal muscles with patient-reported outcome measures in patients with lumbar degenerative disk disease and focal disk prolapse. Global Spine J. 2016;6(4): 401-10.

5. Wan $Q$, Lin C, Li X, Zeng W, Ma C. MRI assessment of paraspinal muscles in patients with acute and chronic unilateral low back pain. Br J Radiol. 2015; 88(1053):20140546.

6. Crawford RJ, Filli L, Elliott JM, Nanz D, Fischer MA, Marcon M, et al. Age- and level-dependence of fatty infiltration in lumbar paravertebral muscles of healthy volunteers. AJNR Am J Neuroradiol. 2016;37(4):742-8.

7. Niemelainen R, Briand MM, Battie MC. Substantial asymmetry in paraspinal muscle cross-sectional area in healthy adults questions its value as a marker of low back pain and pathology. Spine (Phila Pa 1976). 2011;36(25):2152-7.

8. Hides J, Gilmore C, Stanton W, Bohlscheid E. Multifidus size and symmetry among chronic LBP and healthy asymptomatic subjects. Man Ther. 2008; 13(1):43-9.

9. Danneels LA, Vanderstraeten GG, Cambier DC, Witvrouw EE, De Cuyper HJ. CT imaging of trunk muscles in chronic low back pain patients and healthy control subjects. Eur Spine J. 2000;9(4):266-72.

10. Yanik B, Keyik B, Conkbayir I. Fatty degeneration of multifidus muscle in patients with chronic low back pain and in asymptomatic volunteers: quantification with chemical shift magnetic resonance imaging. Skeletal Radiol. 2013:42(6):771-8.

11. Battaglia PJ, Maeda Y, Welk A, Hough B, Kettner N. Reliability of the Goutallier classification in quantifying muscle fatty degeneration in the lumbar multifidus using magnetic resonance imaging. J Manipulative Physiol Ther. 2014;37(3):190-7.

12. Goutallier D, Postel JM, Bernageau J, Lavau L, Voisin MC. Fatty muscle degeneration in cuff ruptures. Pre- and postoperative evaluation by $\mathrm{CT}$ scan. Clin Orthop Relat Res. 1994;304:78-83.

13. Bumann H, Nuesch C, Loske S, Byrnes SK, Kovacs B, Janssen R, et al. Severity of degenerative lumbar spinal stenosis affects pelvic rigidity during walking. Spine J. 2020;20(1):112-20.

14. Shahidi B, Parra CL, Berry DB, Hubbard JC, Gombatto S, Zlomislic V, et al. Contribution of lumbar spine pathology and age to Paraspinal muscle size and fatty infiltration. Spine (Phila Pa 1976). 2017:42(8):616-23.

15. Takayama K, Kita T, Nakamura H, Kanematsu F, Yasunami T, Sakanaka H, et al. New predictive index for lumbar Paraspinal muscle degeneration associated with aging. Spine (Phila Pa 1976). 2016;41(2):E84-90.

16. Fortin M, Videman T, Gibbons LE, Battie MC. Paraspinal muscle morphology and composition: a 15-yr longitudinal magnetic resonance imaging study. Med Sci Sports Exerc. 2014;46(5):893-901.

17. D'Hooge R, Cagnie B, Crombez G, Vanderstraeten G, Dolphens M, Danneels $L$. Increased intramuscular fatty infiltration without differences in lumbar muscle cross-sectional area during remission of unilateral recurrent low back pain. Man Ther. 2012;17(6):584-8.
18. Hu ZJ, He J, Zhao FD, Fang XQ, Zhou LN, Fan SW. An assessment of the intra- and inter-reliability of the lumbar paraspinal muscle parameters using CT scan and magnetic resonance imaging. Spine (Phila Pa 1976). 2011; 36(13):E868-74.

19. Hyun SJ, Bae CW, Lee SH, Rhim SC. Fatty degeneration of the Paraspinal muscle in patients with degenerative lumbar kyphosis: a new evaluation method of quantitative digital analysis using MRI and CT scan. Clin Spine Surg. 2016;29(10):441-7.

20. Sasaki T, Yoshimura N, Hashizume H, Yamada H, Oka H, Matsudaira K, et al. MRI-defined paraspinal muscle morphology in Japanese population: the Wakayama spine study. PLoS One. 2017;12(11):e0187765.

21. Ma J. Dixon techniques for water and fat imaging. J Magn Reson Imaging. 2008;28(3):543-58.

22. Arbanas J, Pavlovic I, Marijancic V, Vlahovic H, Starcevic-Klasan G, Peharec S, et al. MRI features of the psoas major muscle in patients with low back pain. Eur Spine J. 2013;22(9):1965-71.

23. Thompson DD. Aging and sarcopenia. J Musculoskelet Neuronal Interact. 2007;7(4):344-5.

24. Cooper C, Fielding R, Visser M, van Loon LJ, Rolland Y, Orwoll E, et al. Tools in the assessment of sarcopenia. Calcif Tissue Int. 2013:93(3):201-10.

25. Shaw SC, Dennison EM, Cooper C. Epidemiology of sarcopenia: determinants throughout the Lifecourse. Calcif Tissue Int. 2017;101(3):229-47.

26. Sun D, Liu P, Cheng J, Ma Z, Liu J, Qin T. Correlation between intervertebral disc degeneration, paraspinal muscle atrophy, and lumbar facet joints degeneration in patients with lumbar disc herniation. BMC Musculoskelet Disord. 2017;18(1):167.

27. Kang CH, Shin MJ, Kim SM, Lee SH, Lee CS. MRI of paraspinal muscles in lumbar degenerative kyphosis patients and control patients with chronic low back pain. Clin Radiol. 2007;62(5):479-86.

28. Kalichman L, Carmeli E, Been E. The association between imaging parameters of the Paraspinal muscles, spinal degeneration, and low Back pain. Biomed Res Int. 2017;2017:2562957.

\section{Publisher's Note}

Springer Nature remains neutral with regard to jurisdictional claims in published maps and institutional affiliations.

Ready to submit your research? Choose BMC and benefit from:

- fast, convenient online submission

- thorough peer review by experienced researchers in your field

- rapid publication on acceptance

- support for research data, including large and complex data types

- gold Open Access which fosters wider collaboration and increased citations

- maximum visibility for your research: over $100 \mathrm{M}$ website views per year

At BMC, research is always in progress.

Learn more biomedcentral.com/submissions 